Article

\title{
Spatial Distribution Characteristics of Agritourism Consumption
}

\author{
Youxue Jiang * and Shujin Wang * \\ College of Economics and Management, Nanjing Agricultural University, Nanjing 210095, China \\ * Correspondence: 2014206001@njau.edu.cn (Y.J.); wangshujin@njau.edu.cn (S.W.)
}

Received: 23 February 2018; Accepted: 26 March 2018; Published: 28 March 2018

\begin{abstract}
Agritourism is a newly developed type of tourism, which is significant in promoting the sustainable development of rural economies and ecological environments. The spatial distribution of agritourism consumption is an important basis on which to formulate an agritourism development plan. This paper introduces the concept of agritourism consumption, which is applied to develop a theoretical model of spatial distribution based on the analogy that the attraction to agritourism by urban residents is similar to the attraction among charges in physics. With this model, the spatial distribution characteristics of agritourism consumption are investigated under the superposition of multifield sources arising from metropolitan regions. The results indicate that the field strength of agritourism consumption is gradually attenuated with spatial distance. The trend that field strength under multifield sources varies with distance is generally similar to that under a single field source, but the decay rate under multifield sources tends to slow down slightly in different directions. Due to the superposition of multifield sources, the spatial distribution of field strength is no longer in a pattern of concentric circles, but an uneven distribution of contour lines. In addition, there is a positive correlation between field strength distribution and the consumption demand of agritourism.
\end{abstract}

Keywords: agritourism; consumption; field; spatial distribution

\section{Introduction}

Tourism refers to travel for pleasure or business, but it can also refer to the theory and practice of touring, the business of attracting, accommodating, and entertaining tourists, and the business of operating tours [1]. As a newly developed type of tourism [2], agritourism has become an area of interest in terms of investment, and it is significant in improving the health of urban residents and promoting the sustainable development of rural economies and ecological environments [3-5]. In the context of urbanization in China, agritourism locations have been developing rapidly, and the revenue from agritourism has been increasing every year. By the end of 2016, China had created numerous agritourism locations, including 328 demonstration counties (cities, districts), 639 demonstration pilot projects, and 370 beautiful leisure villages. Additionally, 62 items have been identified for their important indigenous agricultural heritage. Although agritourism has made great progress in China (in 2016, the annual business income of national agritourism was 570 billion yuan, with a total of 2.1 billion tourists), the inadequacy of tourist sources is still a universal problem encountered by agritourism parks. This encompasses the problem of consumption capacity and consumption intensity behind the pursuit of leisure and agricultural investment.

With increasing urban populations, urban living spaces are increasingly crowded year by year, which results in many issues such as traffic congestion and life stress. Agritourism has emerged as a favorable choice to experience a "slow life". Agritourism involves any agriculturally based operation or activity that brings visitors to a farm or ranch [6]. The existence of cities has resulted in the accumulation of a strong reserve consumption force for the development of agritourism [7]. 
The strength of this consuming force is analogous to the gravitational field between two electric charges in physics. As long as cities exist, they inevitably bring about the consumption field of agritourism. Once stimulated, the consumption field contributes to agritourism consumption. In that way, the magnitude of urban residents' agritourism consumption intensity directly reflects the consumer field. Although a considerable amount of research has been done on the spatial distribution of agritourism both at home and abroad [8], so far there have been relatively few studies on the spatial distribution of the consumption intensity of agritourism in China based on the theory of physical field.

In recent years, investigation of the tourism field model has mainly focused on determining the urban comprehensive scale and precisely expressing the distance from city centers to peri-urban space [9]. Ferrari et al. [10] applied the gravity model and the spatial interaction model to measure traffic diversion from Ligurian ports, including Savona, La Spezia, and Genoa, to the main Italian and European competitors, in an effort to elucidate the role of distance in drawing hinterland market share to the ports. Geurs [9] reviewed accessibility measures to evaluate transport and land-use strategies, paying particular attention to the distance between an origin and a destination as expressed by transport cost, time, and effort. The available studies analyzed tourism flow behaviors mainly from a distance point of view, and this cannot intuitively describe the spatial interaction of tourism flow. In this context, the concept of the agritourism consumption field is introduced in the current study. Using the concept of electric field in physics, in this paper the agritourism consumption field is considered analogous to the electric field, in an effort to further improve and clarify its connotation.

The consumption field of agritourism reflects the degree of healthy development of agritourism consumption supply, and the prospect of the agritourism industry to a certain extent. The available studies on agritourism are mostly from the perspective of consumption demand behavior, planning layout [11], development path [12], distance decay [13,14], development mode [15], agglomeration degree, and satisfaction degree. Studies on the relationship between consumption field intensity and distance of agritourism and the spatial dependency of consumption field intensity are relatively lacking. In addition, the spatial distribution of the agritourism consumption field strength needs to be further studied, and the superposition effect, which is relatively less understood. The available research has not yet formed a mature qualitative theoretical framework $[16,17]$ or a quantitative measurement model for the consumption field of agritourism [18-20]. It is generally accepted that the consumption field distribution of agritourism is an important basis on which to formulate an agritourism development plan, and a well-organized development plan is beneficial to the sustainable development of rural economy and ecological environment. Considering the importance of agritourism consumption field, it is significant to address the following basic problems: (1) How do we construct a theoretical model of agritourism consumption field? (2) What is the superposition effect in the spatial distribution of the agritourism consumption field strength under multifield sources in metropolitan regions?

In this paper, the electric field model in physics is used to construct a theoretical model of the agritourism consumption field with data from cities of the Yangtze River Delta and the city of Nanjing. Based on this model, the agritourism consumption field strength in each city is measured and its spatial distribution characteristics are expounded. In addition, the spatial distribution patterns of single and multifield sources are respectively deduced and analyzed, which reveals the distribution pattern of agritourism consumption field strength, with a view to optimizing the distribution of agricultural resources and formulating rural development policies according to local conditions so as to provide a scientific reference for the development of agritourism in China.

\section{Theoretical Model}

Agritourism activities are mainly manifested as purposeful spatial reciprocal movements of urban residents between city centers and peri-urban spaces. City centers can be regarded as the source of agritourism flow, and peri-urban can be regarded as diffusion planes for that flow, as shown in Figure 1. The interactions between city centers and peri-urban spaces form an agritourism field. The concentration and diffusion of tourist flows are influenced by the field strength of agritourism, 
which reflects the spatial interactions between city centers and peri-urban spaces. The agritourism consumption characteristics of urban residents in the peri-urban spaces constitute the consumption field of agritourism. Therefore, the consumption field is an important concept of agritourism, and consumption field strength can generally be indicated by expenditure on agritourism per area of peri-urban space.

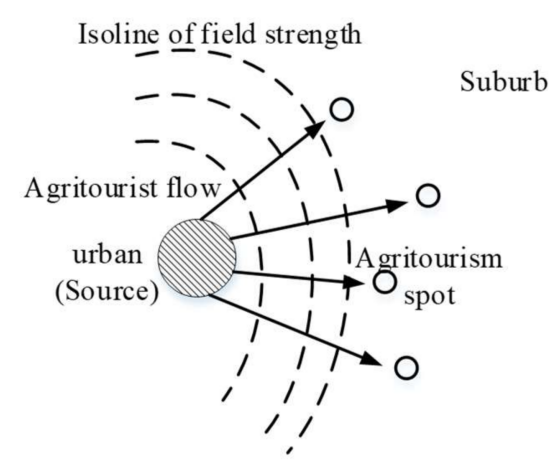

Figure 1. Consumption field of agritourism.

In order to model the consumption behaviors of agritourism, in this study, the agritourism consumption field is seen to be analogous to the electric field generated by a positive electric charge, as illustrated in Figure 2. For one specific point in an electric field generated by a positive electric charge, the larger the quantity of electric charge $(q)$ is, the stronger the electric field strength becomes. Correspondingly, with regard to the consumption field of agritourism, the larger the expenditure of agritourism consumers, the higher the return rate of agritourism investment. In the current study, the sum of agritourism expenditure, $Q$, is defined as the consumption demand charge, which is determined by factors like population size, income, etc., in urban areas and reflects the demand of urban residents for agritourism in peri-urban spaces.

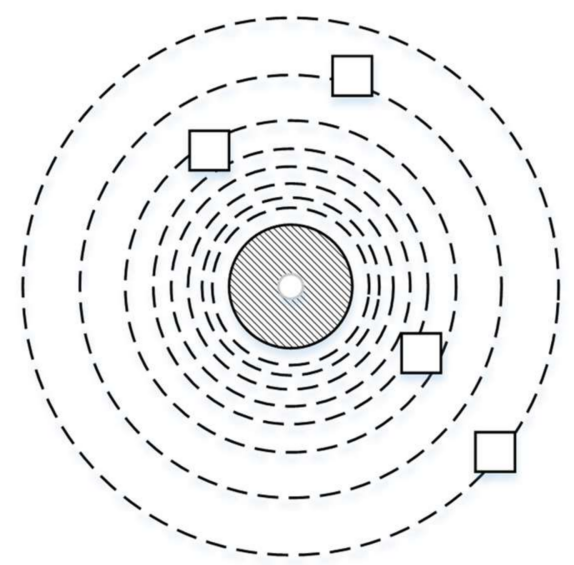

(a)

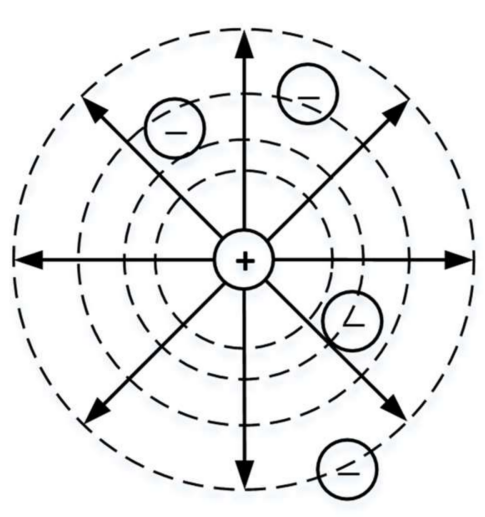

(b)

Figure 2. Consumption field of agritourism. Analogy between agritourism consumption field and electrical field. (a) Agritourism consumption field; (b) electrical field.

In physics, the formula for an electric field generated by electric charges is

$$
\int_{S} E \cdot d S=\frac{q}{\varepsilon_{0}}
$$

where $E$ represents electric field strength, $S$ represents the spatial surface area, $q$ represents the quantity 
of electric charge, and $\varepsilon_{0}$ is a dielectric constant. In electromagnetism, the dielectric constant in a vacuum $\varepsilon_{0}$ indicates the electric field strength generated by isolated electric charge $q$ at a given distance $r$. Since a medium in the applied electric field weakens the electric field by creating induced charge, the dielectric constant defined in the dielectric is $\varepsilon$, of which the ratio to the dielectric constant in a vacuum is defined as a dimensionless relative permittivity, $\varepsilon_{r}=\varepsilon_{0} / \varepsilon$, which indicates the dielectric's capacity to hold the electrical charge. The electric field strength in the dielectric diminishes once materials with larger dielectric constants are placed in the electric field.

Based on the principle of the electric field generated by the electric charge, the attraction of agritourism resources to urban residents is analogous to the attractive force between charges, so a field strength model of agritourism is constructed as follows:

$$
E_{a}=\frac{k_{a} Q}{r_{a}^{2}}
$$

where $E_{a}$ represents the consumption strength at a place in a certain agritourism consumption field, $Q$ represents the agritourism expenditure (i.e., the amount of the tourism-generating region), $k_{a}$ represents the agritourism coefficient, and $r_{a}$ is the distance from the tourism-generating region to the tourist destination. Analogous to the dielectric constant in the electric field constant, $k_{a}$ is used to describe the agritourism consumption field in this study.

In the agritourism consumption field, there is a demand by urban residents for agritourism consumption in the peri-urban spaces. When the infrastructure in the peri-urban spaces around urban areas is in good condition but the traffic and infrastructure in those peri-urban spaces are not well equipped, the urban areas will have a greater consumption demand for agritourism in the peri-urban spaces. This yields a stronger consumption field in the peri-urban spaces. In this case, the agritourism coefficient $k_{a}$ is larger. Conversely, when the peri-urban spaces lack agritourism resources, and the traffic and infrastructure around the urban area are imperfect, the agritourism resources in the peri-urban spaces cannot satisfy the demand of the consumers from the urban areas. In this situation, the agritourism coefficient $k_{a}$ become smaller, and there is a small difference of consumption field in the peri-urban spaces. Accordingly, a higher value of $k_{a}$ represents a broader range of agritourism consumption in the peri-urban space. $k_{a}$ is generally dependent on traffic infrastructure and agritourism resources, which leads to an uneven distribution of agritourism consumption in the peri-urban spaces.

The agritourism field strength model describes the agritourism consumption behaviors of urban residents as a radiation field emitted from the main urban area to the peri-urban spaces, and the field strength for a given peri-urban space is determined by the agritourism expenditure of urban residents and distance from the main urban area. Due to the presence of an agritourism consumption field, a peri-urban space with unique landscape attractions will inspire urban residents to visit. The landscape attraction and distance from the main urban area directly determine how much agritourist entry into a peri-urban space there will be. In other words, once the unique landscape attractions (measured by the agritourism facility value, $q_{a}$ ) are coupled into the field strengthen model, it is possible to characterize the agritourist flow for a peri-urban space. It is generally accepted that, once a particle with electric charge $q_{e}$ is located in an electric field with electric intensity $E_{e}$, the force exerted on the charged particle is $F_{e}=E_{e} q_{e}$ (the subscript e represents the electric field). Similar to the electrical field phenomenon, the received agritourism field radiation owing to landscape attractions for a peri-urban space can be expressed by $F_{a}=E_{a} q_{a}=k_{a} Q q_{a} / r_{a}^{2}$.

In this paper, the model of consumption field considers the agritourism consumption of urban residents as a radiation field emitted from the main urban area, and the spatial interaction of the urban area and the peri-urban spaces are connected through this field. In this way, the consumption field model can comprehensively consider spatial distance, the agritourism consumption expenditure of urban residents, and the agritourism attractions arising from the peri-urban spaces. However, the idea of distance decay only considers the decay of the agritourism consumption field in terms 
of distance. Indeed, the field strength of agritourism consumption for urban residents is delayed with spatial distance. However, as the spatial distance increases, the total consumption in a place is likely to increase, which cannot be explained by the distance decay model. However, the consumption field model can well explain this phenomenon. The greater attractiveness of a place induces a greater driving force for the agritourism flow. In other words, the influence factor of agritourism attractions arising from the peri-urban spaces cannot be considered for the idea of distance decay. Therefore, the consumption field model can more fully reflect the essential characteristics of agritourism than the idea of distance decay.

Policy-making is key to guiding the sustainable development of a region, and the theoretical model proposed in this paper can assist in policy-making. This model can determine the agritourism consumption field for a given region, by which regional sustainable development can be achieved by policy-making. To support agritourism policy, funds are devoted to areas with greater consumption strength so as to concentrate manpower, materials, and financial resources to enhance the agritourism infrastructure, which can promote the development of local agritourism, stimulate economic development in the surrounding areas, and promote sustainable development of the regional economy. When the development of agritourism in a region has reached a certain level, funds should be devoted to areas with smaller consumption strength to promote local agricultural development and realize the coordinated development of the regional economy, which is a significant part of sustainable development. In addition, the environmental damage of tourist destinations caused by unnecessary exploitation could be avoided if resource exploitation were reasonably enhanced in places where consumption strength is strong.

\section{The Research Method}

For a coordinate system of agritourism field shown in Figure 3a, the field strength for the point $q$ $(x, y)$ in the consumption field is only affected by the single field source $Q\left(x_{1}, y_{1}\right)$. According to the formula of agritourism consumption, Equation (2), the field strength at point $q$ produced by a single field source of agritourism consumption demand $Q$ is

$$
E_{a, q}=\frac{k_{a} Q}{\left(x_{1}-x\right)^{2}+\left(y_{1}-y\right)^{2}}
$$

For a point $q(x, y)$ under a two-field source, the consumption field strength is affected by two of the field source demands, $Q_{1}\left(x_{1}, y_{1}\right)$ and $Q_{2}\left(x_{2}, y_{2}\right)$. In this case, the field strength at point $q$ imposed by the two agritourism field sources is

$$
E_{a, q}=\frac{k_{a} Q_{1}}{\left(x_{1}-x\right)^{2}+\left(y_{1}-y\right)^{2}}+\frac{k_{a} Q_{2}}{\left(x_{2}-x\right)^{2}+\left(y_{2}-y\right)^{2}} .
$$

Once there are $n$ cities, the agritourism consumption demand arising from the cities generates a superposition consumption field. As shown in Figure $3 b$, the consumption field strength at point $q$ is the result of a superposition effect of $n$ field source of agritourism consumption demand, $Q_{1}\left(x_{1}, y_{1}\right)$, $Q_{2}\left(x_{2}, y_{2}\right), \ldots$, and $Q_{\mathrm{n}}\left(x_{\mathrm{n}}, y_{\mathrm{n}}\right)$. In this case, the consumption field strength under an $\mathrm{n}$-field source is

$$
E_{a, q}=k_{a} \sum_{i=1}^{n} \frac{Q_{i}}{\left(x_{i}-x\right)^{2}+\left(y_{i}-y\right)^{2}}
$$

Based on the formula of consumption field strength under an n-field source, Equation (5), once the agritourism coefficient $k_{a}$, the coordinates of city center points, and their agritourism consumption demands are given, the field strength distribution of agritourism consumption can be determined. The agritourism coefficient can be determined by the equation $k_{a}=\left(\sum_{i=1}^{n} M_{i} / S_{i}\right) /\left(n \sum_{i=1}^{n} M_{i} / S_{i}\right)$, where $M_{i}$ is the income of agritourism in the $i$ th peri-urban space, $S_{i}$ is the area of the $i$ th peri-urban 
space, and $\sum_{i=1}^{n} M_{i} / S_{i}$ is the sum of the agritourism income and the peri-urban area ratio. Once the agritourism income and peri-urban area are specified, the agritourism coefficient can be determined.

(a)

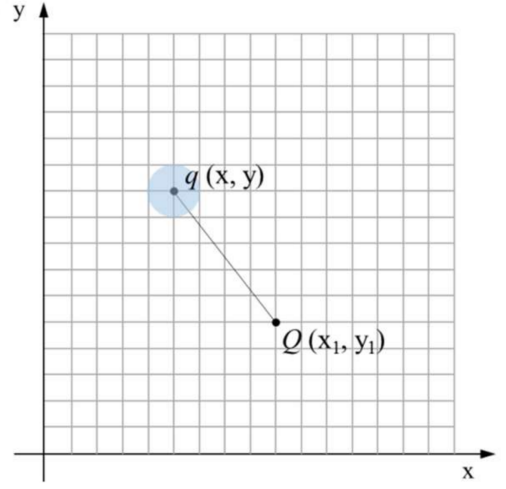

(b)

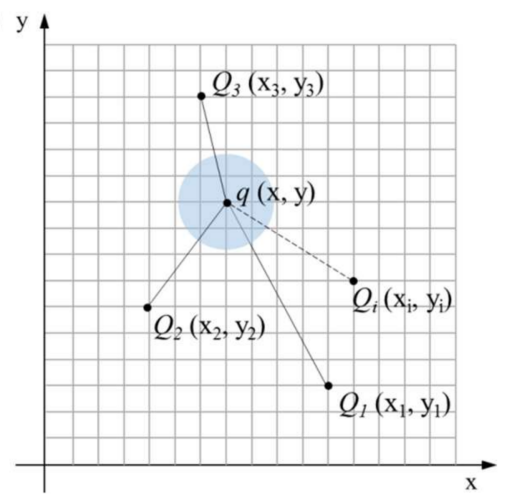

Figure 3. Consumption demand of agritourism: (a) single field source; (b) multifield source.

Figure 4 presents the real consumption strength of agritourism for the towns in Nanjing in the year 2015. Note that the consumption strength is defined by the agritourism operating income per agricultural land area, for which the data comes from the Nanjing Agriculture Commission, the data on agricultural land area comes from Nanjing Land and Resources Bureau, and the distance of towns from Nanjing is measured by Google Maps. As seen from the figure, the real consumption strength of agritourism generally decays with distance from the city. This implies that the distance decay of field strength (see Section 4.2) is approximately in agreement with the real trend of consumption strength. In other words, the approximate agreement of distance decay from geography verifies that the field model proposed in this study is reliable.

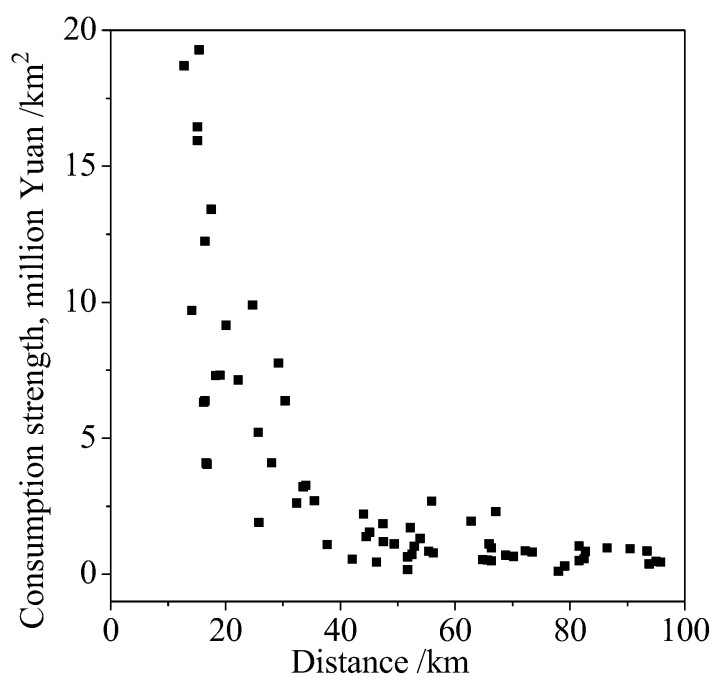

Figure 4. Real consumption strength for the towns in Nanjing.

\section{Spatial Distribution of the Agritourism Consumption Field}

\subsection{The Consumption Field under Multifield Sources}

In order to study the field intensity distribution of multifield source agritourism demand for urban residents, the urban agglomerations of the Yangtze River Delta with a total of 26 cities is selected as a typical case. Figure 5 shows the locations of urban agglomerations of the Yangtze River Delta in China. These 26 cities are Shanghai, Nanjing, Wuxi, Changzhou, Suzhou, Nantong, Yan Cheng, Yangzhou, 
Zhenjiang, Taizhou, Hangzhou, Ningbo, Jiaxing, Huzhou, Taizhou, Hefei, Wuhu, Ma'anshan, Tongling, Anqing, Chuzhou, Chizhou, and Xuancheng. In the current investigation, the agritourism consumption intensity of these cities is measured so as to analyze the spatial distribution characteristics of agritourism in this region. The geocoordinate data (city center), the disposable income per capita, and the total population of the 26 cities in 2015 are considered.

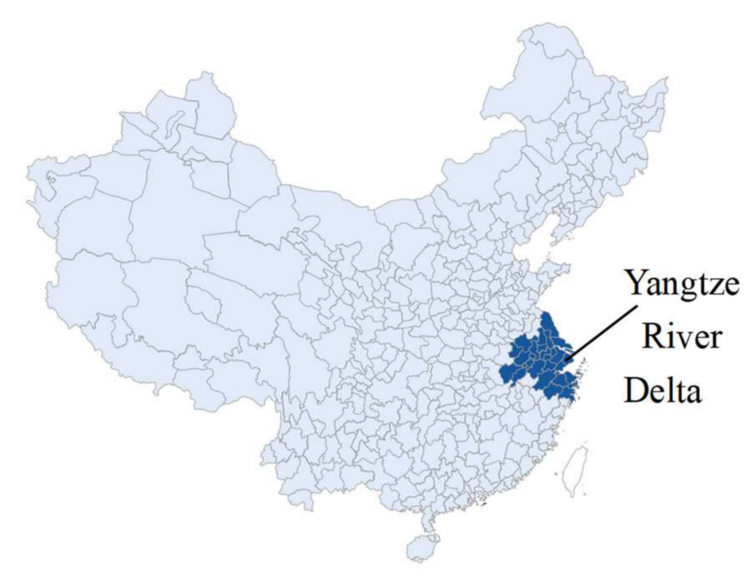

Figure 5. Map of China.

In order to facilitate the representation of the regional range and field strength distribution, a plane coordinate system is established. The positive $x$-axis direction is the east direction, positive $y$-axis direction is the north, and each cell represents a $1 \times 1 \mathrm{~km}$ area. Based on the formula of consumption field strength under an n-field source, Equation (5), the field strength distribution of agritourism consumption can be determined if the agritourism income and peri-urban area are specified. The agritourism income and peri-urban area for the urban agglomerations of the Yangtze River Delta are shown in Figure 6.

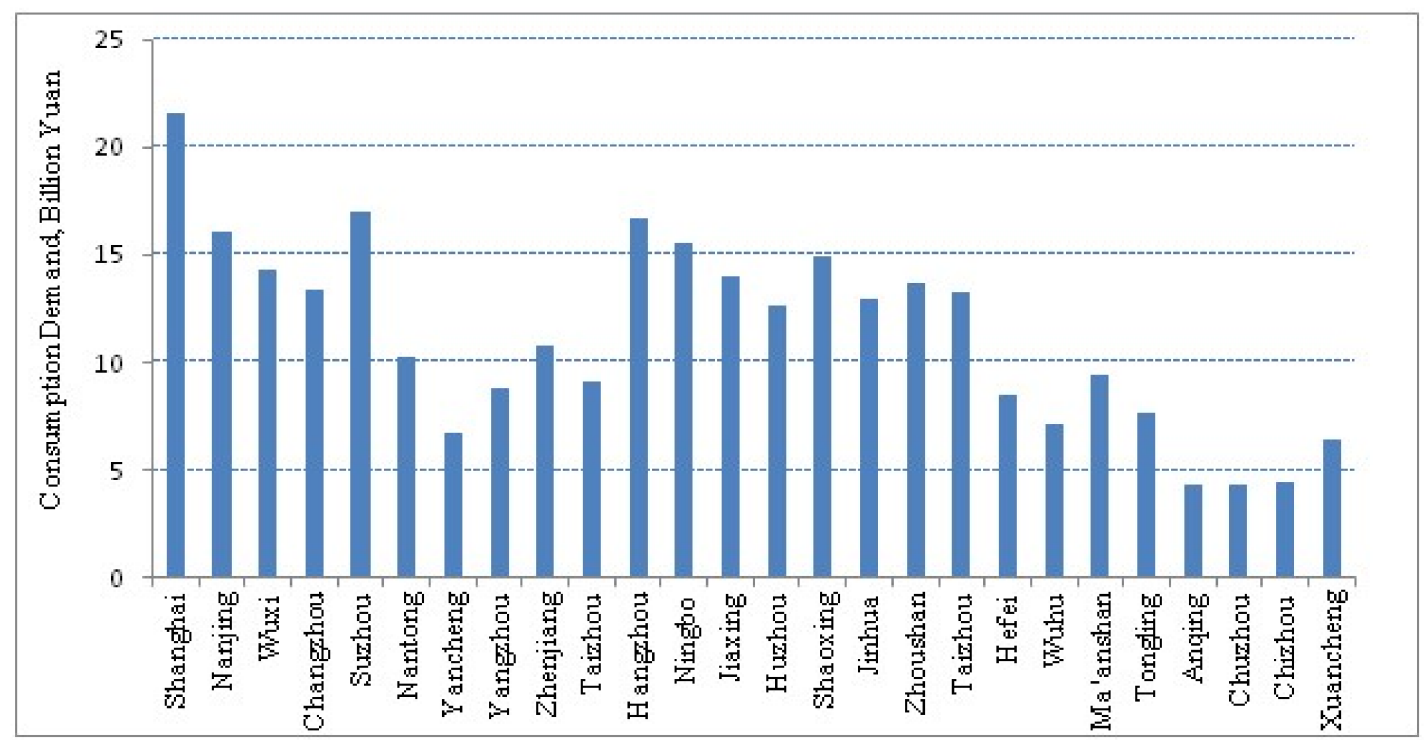

(a) Agritourism income

Figure 6. Cont. 


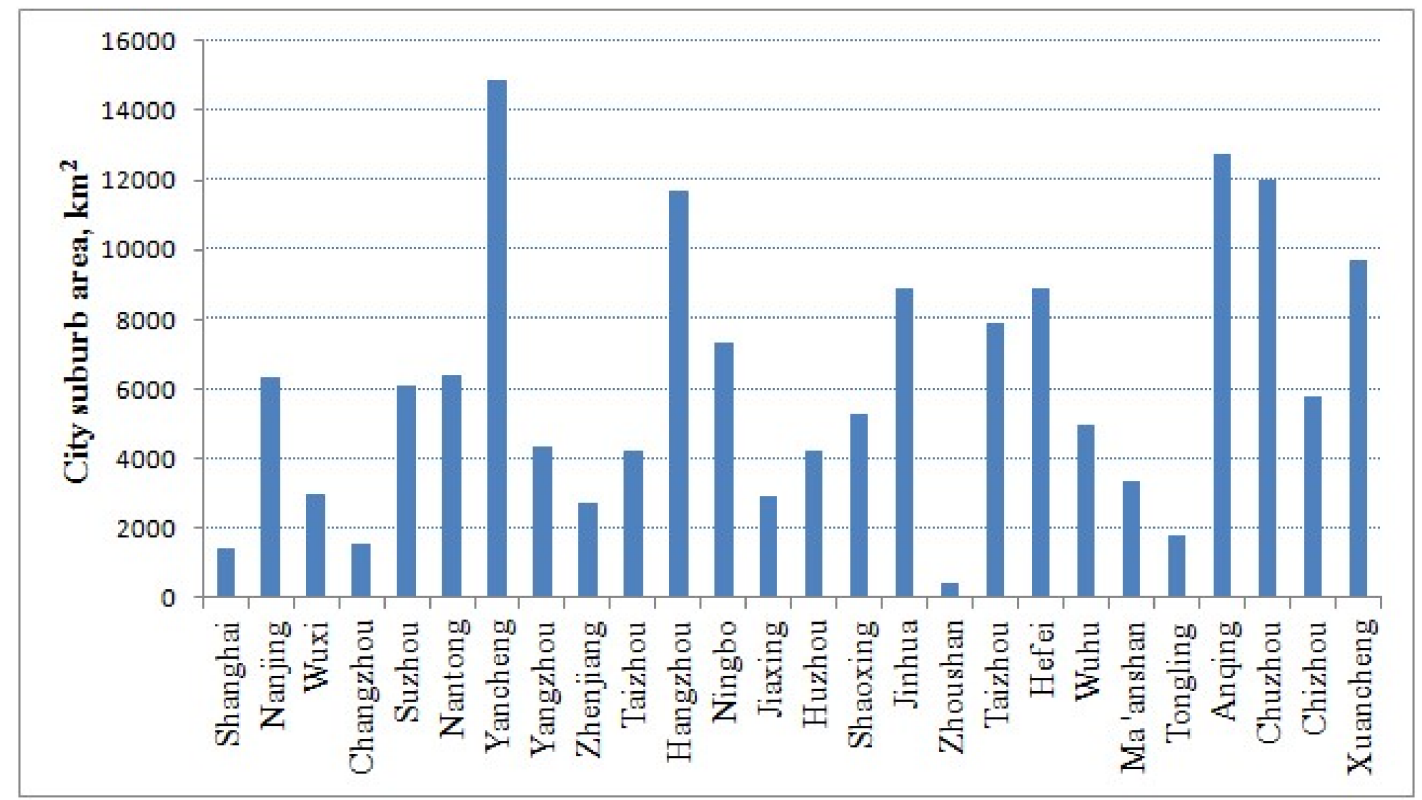

(b) Peri-urban areas

Figure 6. (a) Agritourism income and (b) peri-urban areas for urban agglomerations of Yangtze River Delta.

Figure 7 shows a contour map of field strength distribution for agritourism consumption in the urban agglomeration of the Yangtze River Delta in 2015, in which the equivalent distance of field strength is 1 million yuan $/ \mathrm{km}^{2}$. It can be seen from the figure that there is an uneven distribution of contour lines. On the whole, the contour of the field strength is more densely distributed in Shaoxing, Taizhou, Jinhua, Wuhu, Tongling, Xuancheng, Chuzhou, Yancheng, and Nantong, forming an "isolated island". It is sparser in Zhenjiang, Changzhou, Wuxi, and Suzhou, forming a high field value of the city group. The agritourism consumption demand in Wuxi and Shaoxing was similar, reaching 14.357 billion yuan and 14.984 billion yuan, respectively. However, the distribution of field strength near Shaoxing was significantly more intense than that of Wuxi. This implies that the distribution of agritourism consumption in the urban agglomeration of the Yangtze River Delta is related to its geographical location. Ma'anshan City is adjacent to Wuhu City, and the consumption demand of agritourism in the two cities in 2015 was 9.386 billion yuan and 7.131 billion yuan, respectively. The figure indicates that the field strength contour near Ma'anshan City is sparser than that near Wuhu City, which reflects the positive correlation between field strength distribution and consumption demand of agritourism.

It is worth noting that the value of agritourism consumption in Zhenjiang in 2015 was 10.774 billion yuan, far lower than that of the surrounding Nanjing (161.26 billion yuan), Changzhou (13.413 billion yuan), Wuxi (14.357 billion yuan), and Suzhou (1.721 billion yuan). However, the consumption field strength near Zhenjiang is very strong and its distribution is similar to that of Nanjing, Changzhou, Wuxi, and Suzhou. This implies that the city of Zhenjiang can further develop agritourism consumption resources. 


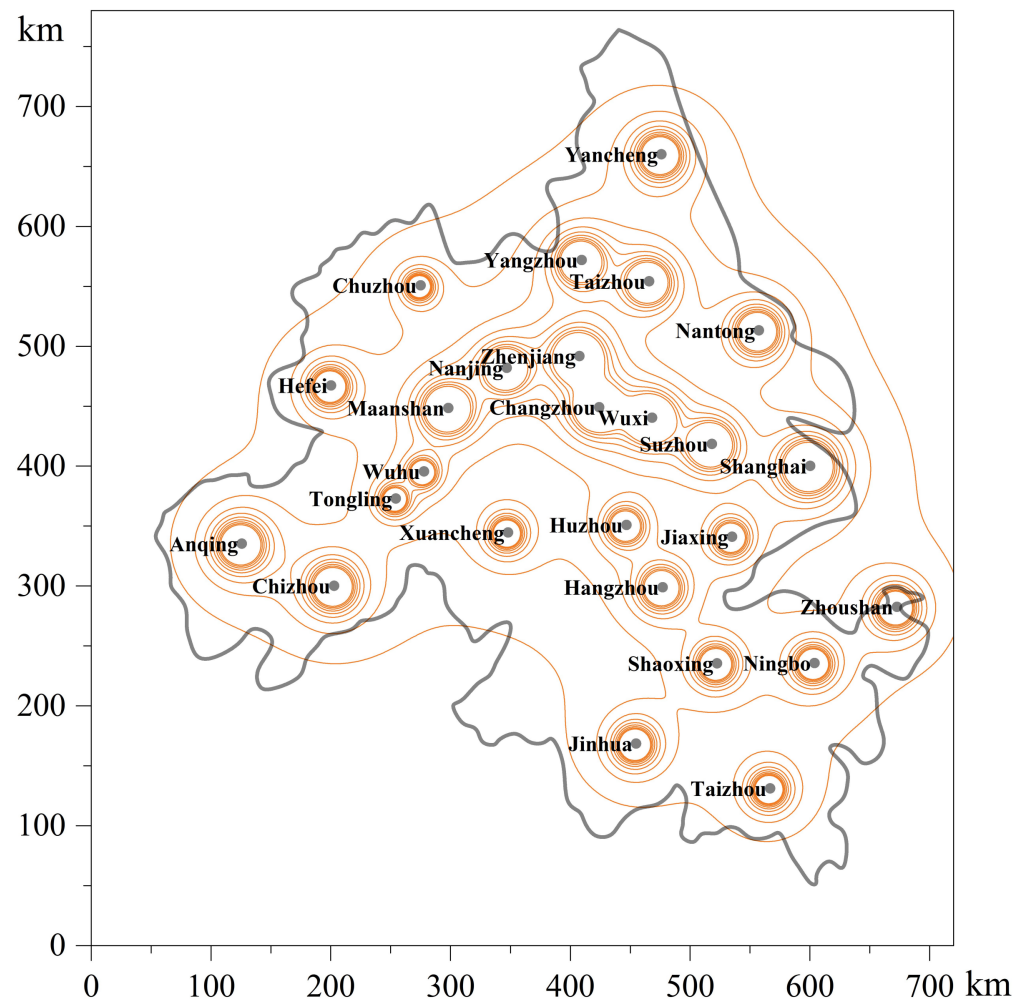

(a)

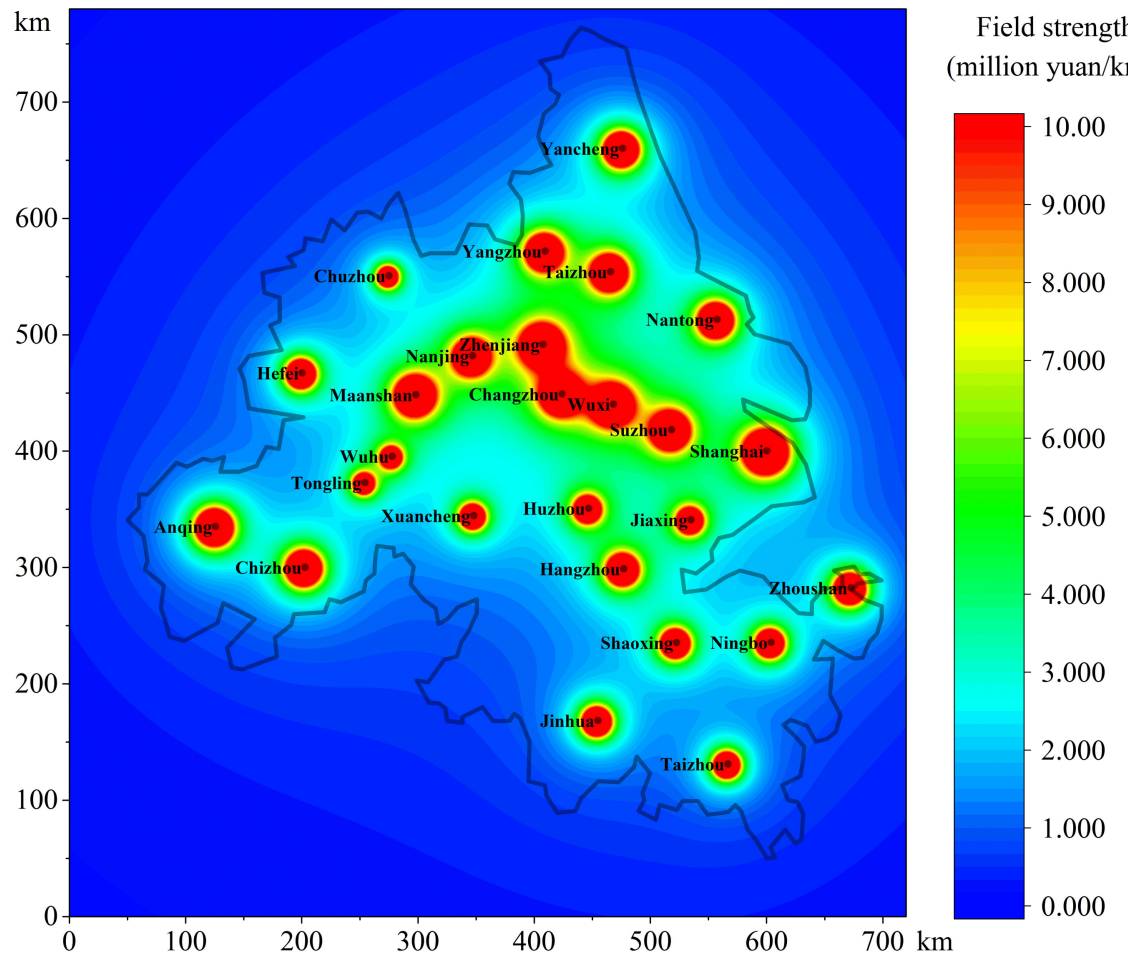

(b)

Figure 7. Field strength distribution for agritourism consumption in the Yangtze River Delta: (a) isogram; (b) contour. 


\subsection{The Consumption Field between Single and Multiple Field Sources}

Nanjing is close to the center of urban agglomeration in the Yangtze River Delta. As the ancient capital of the Six Dynasties, Nanjing has rich and unique agritourism resources and great development potential. In order to study the effect of multifield superposition on the distribution of the local field strength, we choose Nanjing as a typical case and study the changes of its agritourism consumption intensity in different directions.

Figure 8 compares the consumption field of Nanjing agritourism between single and multiple field sources. In the agritourism consumption field formed by a single field source, field strength is inversely proportional to distance. The agritourism consumption shows the change as concentric circles with the city center as a dot. The farther away from the city, the more sparse the field lines and the slower the change trend. The field is very high in the region $20 \mathrm{~km}$ away from the city center. With increasing distance from the peri-urban space, the field strength of agritourism consumption gradually decreases. The center radiation attenuation pattern similar to the positive point charge field is presented as a whole. The field strength of agritourism consumption gradually attenuates with distance. From the border of the urban area to $20 \mathrm{~km}$ away from the city center, the field strength shows a rapid decline. The value of field strength decreases from 30 million yuan $/ \mathrm{km}^{2}$ down to 10 million yuan $/ \mathrm{km}^{2}$. At a distance of $20-40 \mathrm{~km}$ from the city center, the decay rate gradually slows down. At a distance of $20 \mathrm{~km}$, there is an inflection point where the value of the field strength is about 6 million yuan $/ \mathrm{km}^{2}$. At a distance of $40 \mathrm{~km}$ from the city center, the field strength changes slowly and gradually approaches 0 .

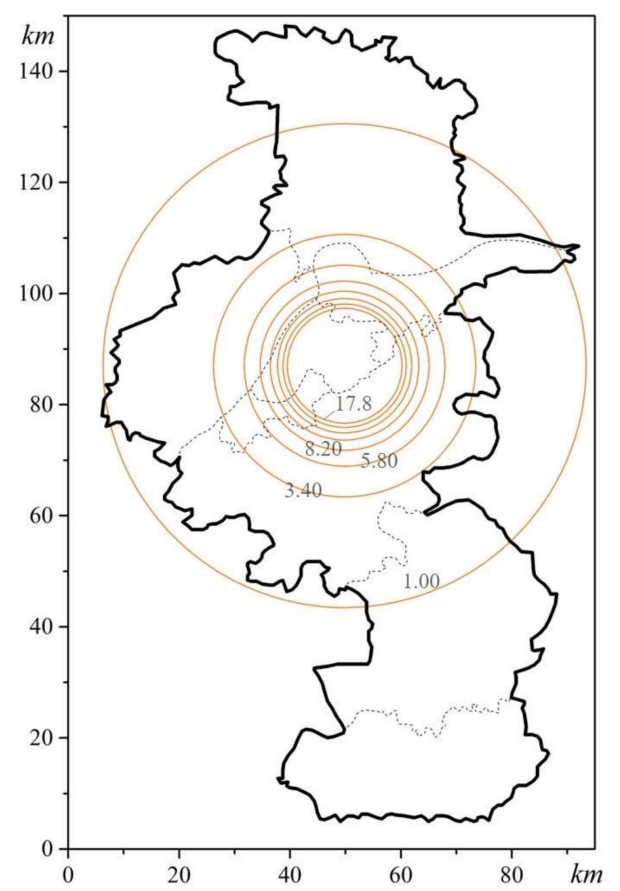

(a)

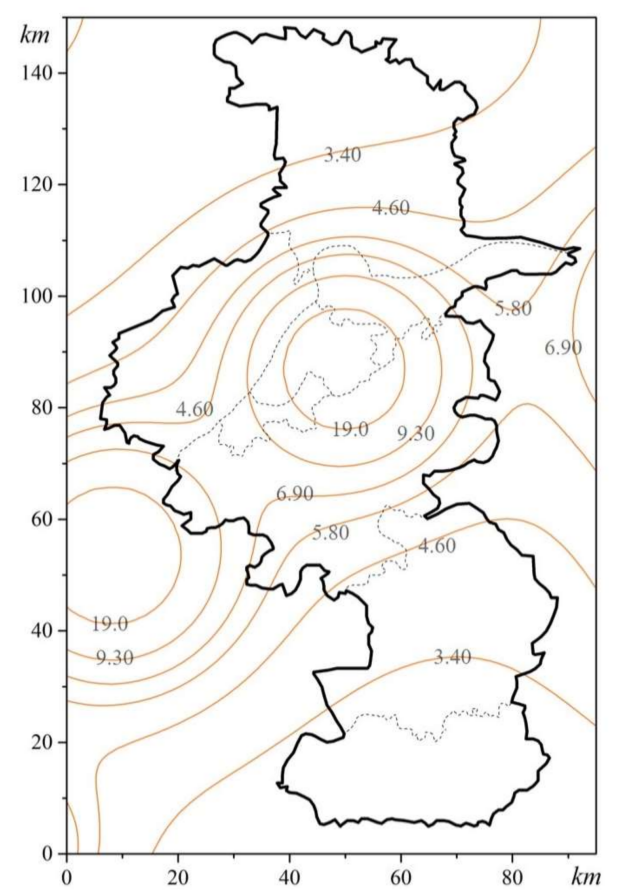

(b)

Figure 8. Field strength distribution of agritourism consumption for Nanjing: (a) single field source; (b) multiple field source.

As can be seen from Figure 8, in the case of multifield superposition, the consumption intensity of agritourism in Nanjing presents a central radiation decay pattern similar to that of an electric charge field as a whole, that is, the consumption field strength of agritourism decays in all directions with the urban area as the center. In the southwest and east, affected by market sources in Ma'anshan and Zhenjiang, the decay rate is slower than in other directions. Due to the superposition of multifield 
sources, the spatial distribution of field strength is no longer in the fashion of concentric circles but in an uneven distribution of contour lines.

To provide further insight into the field strength characteristics of agritourism consumption in all directions, taking the Nanjing municipal government as the center, the east direction is $0^{\circ}$, and the counterclockwise direction is the positive direction. The three angles of $60^{\circ}, 180^{\circ}$, and $300^{\circ}$ are selected as the typical case to analyze agritourism consumption field strength, as shown in Figure 9a. It is assumed that the main urban area of Nanjing does not have agritourism resources, so its consumption intensity should be zero. In order to simplify the influence of the urban geographic shape, it is supposed that the main urban shape is a circle, with the Nanjing government as the center, and the radius is calculated by $r_{0}=(S / \pi)^{1 / 2}$, where $S$ is the main urban area, and $r_{0}$ represents the urban radius $\left(r_{0}=9 \mathrm{~km}\right.$ for Nanjing).

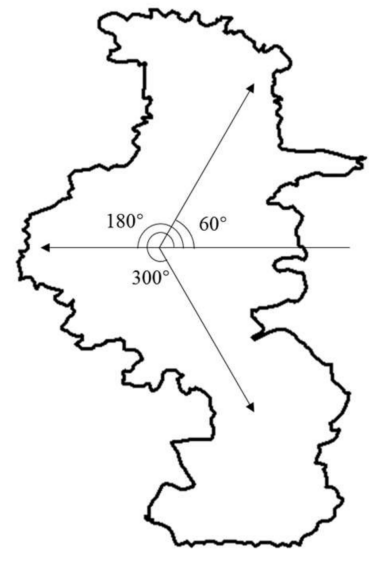

(a)

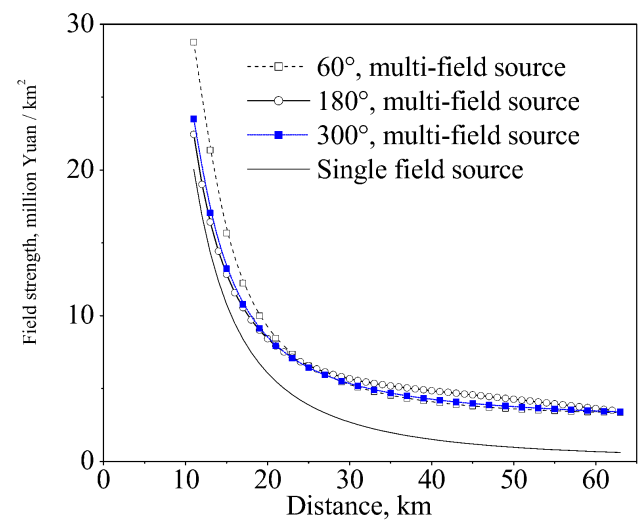

(b)

Figure 9. Agritourism consumption strength of Nanjing in different directions: (a) schematic of direction; (b) variation of field strength.

In order to study the influence of multifield sources on the consumption strength of agritourism, Figure $9 \mathrm{~b}$ shows field strength as a function of distance from the Nanjing urban area in different directions. Generally, agritourism sites are farther than 10-15 km from a city center. As a consequence, the data on agritourism consumption strength within $10 \mathrm{~km}$ is not considered in the plot. For the agritourism consumption field formed by superposition of multiple field sources (the Yangtze River Delta urban agglomeration), the variation of field strength with distance is generally similar to that of a single field source, and the decay rate tends to slow down slightly in different directions. Within $20 \mathrm{~km}$ from the city center, the field strength in three directions rapidly decays with distance, changing most in the $60^{\circ}$ direction, from 43 million yuan $/ \mathrm{km}^{2}$ to 9 million yuan $/ \mathrm{km}^{2}$. The field strength in the $300^{\circ}$ direction changes minimally from 30 million yuan $/ \mathrm{km}^{2}$ to 8 million yuan $/ \mathrm{km}^{2}$. The field strength in these three directions reached the same value of 7 million yuan $/ \mathrm{km}^{2}$ at a distance of $25 \mathrm{~km}$ from the city center. At a distance of $40 \mathrm{~km}$ from the city center, the field strength changes slowly in the three directions, and the field strength at the same distance from the city center is almost the same.

It can be seen from the above analysis that agritourism resources within $20 \mathrm{~km}$ from the center of Nanjing can continue to be developed, and development in the northeast can bring greater economic benefits. In the area $40 \mathrm{~km}$ away from the city center, all directions are basically homogeneous and need to be further developed based on the historical and cultural resources as well as the natural resources, in an effort to form a local characteristic agritourism product. In addition, within the scope of Nanjing, field strength in the directions of $60^{\circ}, 180^{\circ}$, and $300^{\circ}$ is less affected by other field sources than outside Nanjing, so field strength tends to decay with overall distance. However, in the directions of $0^{\circ}$ and $210^{\circ}$, the field strength farther from the center of Nanjing will increase due to the greater 
impact from the two field sources, Zhenjiang and Ma'anshan. Therefore, agritourism resources also need to be further developed in these two directions.

\section{Discussion}

The concept of consumption field is introduced to intuitively describe the spatial interaction of agritourism flow in this paper. Field is a form of interaction that can describe the spatial and temporal trajectories and characteristics of tourism consumption among cities. Field strength is an original concept in mechanics. Similarly applied to economic activities, the central city's attraction is called an urban influence and a magnitude of influence is called field strength. Each city has a core area, and this is usually known as the main urban area. The impact of main urban areas on the surrounding peri-urban space resembles field strength in physics and is utilized to measure the impact of the urban areas on the peri-urban spaces. The model of tourism field strength originates from the gravity model in physics. Crampon [21] firstly proposed the tourism gravity model based on Newton's law of gravitation, and held the opinion that tourism for a place depends on the population size and wealth of the tourism-generating region, the attraction of the destination, and the distance between the tourism-generating region and the destination. Scholars also support this opinion in their study of tourism demand [22,23], destination accessibility [16], and distance decay [24], and eastern European countries' potential trade [25]. The tourism gravity model is a typical paradigm to study distance decay in tourism and to analyze the corresponding influence factors.

Based on the analogy that the attraction to agritourism by urban residents is similar to the attraction among charges in physics, a theoretical model of spatial distribution of agritourism consumption was developed. The proposed model in the current study is in general for the analysis of the spatial distribution of agritourism consumption under the superposition of multifield sources arising from metropolitan regions. In order to provide an intuitionistic exhibition of the field intensity distribution of multi-field source agritourism demand for the urban resident, the urban agglomerations of the Yangtze River Delta was selected here as a typical case. It should be noted that the proposed model is effective not only in the urban agglomerations of Yangtze River Delta but also in other regions.

Using the proposed theoretical model, we can determine the spatial distribution of agritourism consumption and hence assist policy-making for regional sustainable development. When a new agritourism location is being developed in an area, we need to comprehensively consider the spatial distance, the agritourism consumption expenditure of urban residents, and the landscape attractions arising from peri-urban spaces. According to the distance decay characteristics of agritourism consumption, a new agritourism location closer to the city center is a good candidate; it is especially preferred to develop new agritourism locations in peri-urban spaces considered close to city centers (where the distance away from the city center is less than $20 \mathrm{~km}$ ). In addition, the resource exploitation of agritourism locations should be reasonably enhanced in places with strong consumption strength. For agritourism locations in peri-urban spaces considered far from city centers (the distance away from the city center lies between 20 and $60 \mathrm{~km}$ ), the spatial distance is of less importance to the field strength of the agritourism consumption, i.e., the field strength is almost insensitive to spatial distance. In this case, the policy-maker should pay special attention to landscape attractions, rather than distance, when several regions compete to develop new agritourism locations in peri-urban spaces far from city centers. Therefore, specific recommendations for policy makers are as follows: New agritourism locations should be located in peri-urban spaces close to city centers. However, for agritourism locations in peri-urban spaces considered far from city centers, special attention should be paid to landscape attractions rather than distance.

\section{Conclusions and Future Work}

In this paper, the concept of consumption field is introduced to intuitively describe the spatial interaction of agritourism flow. Using the definition of electric field in physics, so as to further improve and clarify the connotation of field strength for agritourism consumption, the agritourism consumption 
field is said to be analogous to the electric field. Based on this analogy, a theoretical model of the agritourism consumption field is developed. The proposed theoretical model was tested by real consumption strength with towns in Nanjing. The consumption field of agritourism was measured, and the superposition effect of agritourism consumption field and distance attenuation is explained. In addition, the spatial distribution characteristics of agritourism consumption field under single and multifield sources are compared and analyzed. The proposed model can in general be used to analyze the spatial distribution of agritourism consumption under the superposition of multifield sources arising from metropolitan regions, which is not only effective in the urban agglomerations of Yangtze River Delta but also effective in other regions. The main conclusions are as follows:

(1) Under a single field source, the field strength of agritourism consumption shows a change of concentric circles with the city center and gradually attenuates with distance. The field strength is very high in the region $20 \mathrm{~km}$ away from the city center.

(2) Although the trend that field strength of agritourism consumption under multifield sources varies with distance is generally similar to that under a single field source, the decay rate under multifield sources tends to slow down slightly in different directions. In addition, due to superposition of multifield sources, the spatial distribution of field strength is no longer in the fashion of concentric circles, but an uneven distribution of contour lines.

(3) When a new agritourism location is being developed in an area, policy-makers should select agritourism locations peri-urban spaces close to the city center. However, for agritourism locations in peri-urban spaces far from city centers, special attention should be paid to landscape attractions, rather than distance.

(4) Under the effect of multifield sources, there is an uneven distribution of contour lines for the field strength of agritourism consumption. Taking the Yangtze River Delta urban agglomeration as an example, on the whole, the contour of field strength is more densely distributed in Shaoxing, Taizhou, Jinhua, Wuhu, Tongling, Xuancheng, Chuzhou, Yancheng, and Nantong, forming an "isolated island". It is sparser in Zhenjiang, Changzhou, Wuxi, and Suzhou, forming a high field value of the city group. There is a positive correlation between field strength distribution and consumption demand of agritourism.

This paper investigates the spatial distribution characteristics of the agritourism consumption field, using the cities of the Yangtze River Delta urban agglomeration and Nanjing as a typical case for analysis. From this study, we can conclude that the consumption field is effective for describing the spatial interaction of agritourism spatial distribution. In addition, the formula to calculate consumption field strength can determine radiation strength from main urban areas to peri-urban spaces, which can also be applied to determine agritourism attractions arising from the peri-urban spaces. However, in general, the present study is preliminary, obtaining a formula of consumption fields as well as spatial interactions between tourism-generating regions and tourist destinations by considering electrical fields as analogous to agritourism fields. The logic of science informs us that the agritourism demand field will stimulate its supply field, and a change in supply field will also induce a change in demand field. This implies that the agritourism demand field and supply field are implicitly coupled, and this requires expression by a partial differential equation. Further work can aim to study the agritourism flow behaviors in different social and economic conditions using the empirical study of agritourism consumption field, in an effort to improve and perfect the theory of agritourism consumption field in metropolitan regions.

Acknowledgments: This work was supported by the National Natural Science Foundation of China (No. 71273137) and the Research Innovation Program for College Graduates of Jiangsu Province (Grant No. KYLX16_0981).

Author Contributions: Y.J. and S.W. conceived and designed the research; Y.J. analyzed the data; Y.J. and S.W. wrote the paper.

Conflicts of Interest: The authors declare no conflict of interest. 


\section{References}

1. Simpson, J.; Weiner, E.S. The Oxford English Dictionary, 3rd ed.; Clarendon Press: Oxford, UK, 2005.

2. Eilat, Y.; Einav, L. Determinants of international tourism: A three-dimensional panel data analysis. Appl. Econ. 2004, 36, 1315-1327. [CrossRef]

3. Phillip, S.; Hunter, C.; Blackstock, K. A typology for defining agritourism. Tour. Manag. 2010, 31, 754-758. [CrossRef]

4. Genovese, D.; Culasso, F.; Giacosa, E.; Battaglini, L.M. Can Livestock Farming and Tourism Coexist in Mountain Regions? A New Business Model for Sustainability. Sustainability 2017, 9, 2021. [CrossRef]

5. Broccardo, L.; Culasso, F.; Truant, E. Unlocking Value Creation Using an Agritourism Business Model. Sustainability 2017, 9, 1618. [CrossRef]

6. Biuso, E. Down on the Farm with Your Sleeves Rolled Up; The New York Times: New York, NY, USA, 2007.

7. Park, D.-B.; Yoon, Y.-S. Segmentation by motivation in rural tourism: A Korean case study. Tour. Manag. 2009, 30, 99-108. [CrossRef]

8. Papatheodorou, A. Exploring the evolution of tourism resorts. Ann. Tour. Res. 2004, 31, 219-237. [CrossRef]

9. Geurs, K.T.; Van Wee, B. Accessibility evaluation of land-use and transport strategies: Review and research directions. J. Transp. Geogr. 2004, 12, 127-140. [CrossRef]

10. Ferrari, C.; Parola, F.; Gattorna, E. Measuring the quality of port hinterland accessibility: The Ligurian case. Transp. Policy 2011, 18, 382-391. [CrossRef]

11. Van der Merwe, J.; Ferreira, S.; Van Niekerk, A. Resource-directed spatial planning of agritourism with GIS. S. Afr. Geogr. J. 2013, 95, 16-37. [CrossRef]

12. Nepal, S.K. Tourism and rural settlements Nepal's Annapurna region. Ann. Tour. Res. 2007, 34, 855-875. [CrossRef]

13. Choi, A.S. Nonmarket values of major resources in the Korean DMZ areas: A test of distance decay. Ecol. Econ. 2013, 88, 97-107. [CrossRef]

14. León, C.J.; Araña, J.E.; de León, J.; González, M.M. The economic benefits of reducing the environmental effects of landfills: Heterogeneous distance decay effects. Environ. Resour. Econ. 2016, 63, 193-218. [CrossRef]

15. Dorocki, S.; Rachwał, T.; Szymańska, A.I.; Zdon-Korzeniowska, M. Spatial conditions for agritourism development on the example of Poland and France. Curr. Issues Tour. Res. 2013, 2, 20-29.

16. Hooper, J. A destination too far? Modelling destination accessibility and distance decay in tourism. GeoJournal 2015, 80, 33-46. [CrossRef]

17. Chen, Y. The distance-decay function of geographical gravity model: Power law or exponential law? Chaos Solitons Fractals 2015, 77, 174-189. [CrossRef]

18. Berry, B.J.; Lamb, R.F. The delineation of urban spheres of influence: Evaluation of an interaction model. Reg. Stud. 1974, 8, 185-190. [CrossRef]

19. Rossi, S.D.; Byrne, J.A.; Pickering, C.M. The role of distance in peri-urban national park use: Who visits them and how far do they travel? Appl. Geogr. 2015, 63, 77-88. [CrossRef]

20. González-Ramiro, A.; Gonçalves, G.; Sánchez-Ríos, A.; Jeong, J.S. Using a VGI and GIS-based multicriteria approach for assessing the potential of rural tourism in Extremadura (Spain). Sustainability 2016, 8, 1144. [CrossRef]

21. Crampon, L. A new technique to analyze tourist markets. J. Mark. 1966, 30, 27-31. [CrossRef]

22. Morley, C.; Rosselló, J.; Santana-Gallego, M. Gravity models for tourism demand: Theory and use. Ann. Tour. Res. 2014, 48, 1-10. [CrossRef]

23. Chasapopoulos, P.; den Butter, F.A.; Mihaylov, E. Demand for tourism in Greece: A panel data analysis using the gravity model. Int. J. Tour. Policy 2014, 5, 173-191. [CrossRef]

24. Mckercher, B.; Lew, A.A. Distance decay and the impact of effective tourism exclusion zones on international travel flows. J. Travel Res. 2003, 42, 159-165. [CrossRef]

25. Ravishankar, G.; Stack, M.M. The gravity model and trade efficiency: A stochastic frontier analysis of Eastern European countries' potential trade. World Econ. 2014, 37, 690-704. [CrossRef]

(C) 2018 by the authors. Licensee MDPI, Basel, Switzerland. This article is an open access article distributed under the terms and conditions of the Creative Commons Attribution (CC BY) license (http:/ / creativecommons.org/licenses/by/4.0/). 